\title{
Hydrate-based carbon dioxide capture from simulated integrated gasification combined cycle gas
}

\author{
Chungang $\mathrm{Xu}^{1,2,3}, \quad$ Xiaosen $\mathrm{Li}^{1,2 *}$ ， Jing Cai ${ }^{1,2}, \quad$ Zhaoyang Chen ${ }^{1,2}$ \\ 1. Key Laboratory of Renewable Energy and Gas Hydrate, Guangzhou Institute of Energy Conversion, Chinese Academy of Sciences, Guangzhou 510640, \\ Guandong, China; 2. Guangzhou Center for Gas Hydrate Research, Chinese Academy of Sciences, Guangzhou 510640, Guangdong, China, \\ 3. Graduate University of Chinese Academy of Sciences, Beijing 100083, China \\ [ Manuscript received March 2, 2012; revised April 6, 2012]
}

\begin{abstract}
The equilibrium hydrate formation conditions for $\mathrm{CO}_{2} / \mathrm{H}_{2}$ gas mixtures with different $\mathrm{CO}_{2}$ concentrations in 0.29 mol\% TBAB aqueous solution are firstly measured. The results illustrate that the equilibrium hydrate formation pressure increases remarkably with the decrease of $\mathrm{CO}_{2}$ concentration in the gas mixture. Based on the phase equilibrium data, a three stages hydrate $\mathrm{CO}_{2}$ separation from integrated gasification combined cycle (IGCC) synthesis gas is investigated. Because the separation efficiency is quite low for the third hydrate separation, a hybrid $\mathrm{CO}_{2}$ separation process of two hydrate stages in conjunction with one chemical absorption process (absorption with MEA) is proposed and studied. The experimental results show $\mathrm{H}_{2}$ concentration in the final residual gas released from the three stages hydrate $\mathrm{CO}_{2}$ separation process was approximately $95.0 \mathrm{~mol} \%$ while that released from the hybrid $\mathrm{CO}_{2}$ separation process was approximately $99.4 \mathrm{~mol} \%$. Thus, the hybrid process is possible to be a promising technology for the industrial application in the future.
\end{abstract}

Key words

integrated gasification combined cycle (IGCC); gas hydrate; $\mathrm{CO}_{2}$ separation; $\mathrm{H}_{2}$ purification; chemical absorption

\section{Introduction}

Carbon dioxide $\left(\mathrm{CO}_{2}\right)$ is considered as one main contributor to the greenhouse gases resulting in the global warming [1]. Near one third of all $\mathrm{CO}_{2}$ emissions worldwide is produced by the fuel power plants [2]. Therefore, the prime target is to capture $\mathrm{CO}_{2}$ from the fuel power plants to slow down the deterioration of the climate. Pre-combustion capture and post-combustion capture are two approaches extensively used for $\mathrm{CO}_{2}$ capture from the fuel power plants [3]. Pre-combustion capture is capturing or removing $\mathrm{CO}_{2}$ before the fuel being burnt while post-combustion capture is capturing or removing $\mathrm{CO}_{2}$ from the flue gas [4]. Presently, the integrated gasification combined cycle (IGCC) is widely utilized in the coal-fired power plants. $\mathrm{CO}_{2}$ capture from IGCC becomes one promising route of pre-combustion capture. In IGCC plant, coal is firstly gasified and then converted into a stream of hydrogen $\left(\mathrm{H}_{2}\right)$ and $\mathrm{CO}_{2}$ [5]. Once $\mathrm{CO}_{2}$ is removed efficiently, the resultant $\mathrm{H}_{2}$ can be used as a clean fuel. Physical adsorption, chemical absorption, cryogenic fractionation and membrane process are the conventional technologies for capturing $\mathrm{CO}_{2}$ from the fuel gas. However, the conventional technologies face some challenges, such as low capacity, technology feasibility, high cost and corrosion [6,7]. Therefore, novel and low cost technologies of carbon capture need to be developed.

Gas hydrate-based $\mathrm{CO}_{2}$ capture technology is one of the novel technologies for capturing $\mathrm{CO}_{2}$ from IGCC synthesis gas (mixture of $\mathrm{CO}_{2} / \mathrm{H}_{2}$ ). The gas hydrates are nonstoichiometric compounds formed by water molecules and small molecule gases such as $\mathrm{CO}_{2}$, nitrogen $\left(\mathrm{N}_{2}\right)$, oxygen $\left(\mathrm{O}_{2}\right), \mathrm{H}_{2}$, methane $\left(\mathrm{CH}_{4}\right)$ [8]. The mechanism of hydratebased $\mathrm{CO}_{2}$ capture is selective partition of $\mathrm{CO}_{2}$ component between hydrate phase and gaseous phase $[9,10]$. Because the equilibrium hydrate formation pressure of $\mathrm{CO}_{2}$ is much lower than that of $\mathrm{H}_{2}$ at the same temperature, it is expected that

\footnotetext{
* Corresponding author. Tel: +86-20-87057037; Fax: +86-20-87034664; E-mail: lixs@ms.giec.ac.cn

This work was supported by the National Natural Science Foundation of China (51076155) and Science \& Technology Program of Guangdong Province (2009B050600006).
} 
$\mathrm{CO}_{2}$ is preferentially encaged into the hydrate phase. The hydrates are then separated and subsequently decomposed to create $\mathrm{CO}_{2}$-rich stream while the rest constitutes $\mathrm{CO}_{2}$-lean one. Thereby, $\mathrm{CO}_{2}$ is captured from IGCC synthesis gas.

IGCC synthesis gas mainly contains approximately $40.0 / 60.0 \mathrm{~mol} \% \mathrm{CO}_{2} / \mathrm{H}_{2}$ gas mixture, and the outlet pressure of the synthesis gas is generally $3-5 \mathrm{MPa}$ [3]. In our previous work [10], the concentration of $\mathrm{CO}_{2}$ can be reduced from $40.0 \mathrm{~mol} \%$ in the feed gas to approximately $13.5 \mathrm{~mol} \%$ in the residual gas after one stage hydrate-based $\mathrm{CO}_{2}$ separation. Therefore, in order to separate $\mathrm{CO}_{2}$ from $\mathrm{CO}_{2} / \mathrm{H}_{2}$ gas mixture completely, two hydrate stages or even three hydrate stages are required. However, the equilibrium hydrate formation pressure is higher with the decrease of $\mathrm{CO}_{2}$ concentration in the gas mixture. Thus, higher driving forces are required for the gas mixtures containing lower concentration of $\mathrm{CO}_{2}$ to form gas hydrate, that is, more serious conditions are required for the gas mixtures containing lower concentration of $\mathrm{CO}_{2}$ to form gas hydrate. Therefore, a hybrid process based on the hydrate and chemical absorption process is developed. Moreover, no complete system configurations with key hybrid process parameters were presented in the papers $[11,12]$.

In our previous work, $0.29 \mathrm{~mol} \%$ TBAB solution was proved to be an optimal hydrate formation promoter for the hydrate-based $\mathrm{CO}_{2}$ capture from either flue gases or IGCC synthesis gas [9]. Thus, $0.29 \mathrm{~mol} \%$ TBAB solution is adopted in this work directly. In addition, the equilibrium hydrate formation conditions for $\mathrm{CO}_{2} / \mathrm{H}_{2} / \mathrm{TBAB} / \mathrm{H}_{2} \mathrm{O}$ systems with different $\mathrm{CO}_{2}$ concentrations are measured firstly, and a hybrid process based on two hydrate stages coupled with a chemical absorption process is proposed for $\mathrm{CO}_{2}$ capture. By the comparison of $\mathrm{CO}_{2}$ capture efficiencies, the concentrations of $\mathrm{H}_{2}$ in the residual gas, the energy consumptions between the third-stage hydrate-based $\mathrm{CO}_{2}$ separation process and the hybrid process, and an optimal separation process are determined.

\section{Experimental}

\subsection{Materials}

A $\mathrm{CO}_{2} / \mathrm{H}_{2}$ gas mixture containing $39.6 \mathrm{~mol} \% \mathrm{CO}_{2}$ was used in the work to simulate a pretreated fuel gas mixture. The gas mixture was supplied by Foshan Huate Gas Co., Ltd. Tetra- $n$-butyl ammonium bromide (TBAB) with $99.9 \%$ purity was supplied by Shanghai Sinopharm Chemical Reagent Co., Ltd., China. Monoethanolamine (MEA) with the purity of more than $99.0 \%$ was offered by Tianjin Fuyu Fine Chemicals Co., Ltd. The deionized water used with the resistivity of $18.25 \mathrm{~m} \quad / \mathrm{cm}$ was produced by an ultra-pure water system supplied by Nanjing Ultrapure Water Technology Co., Ltd., China. The glass-balls with the diameter of $3 \mathrm{~mm}$ were supplied by Yunhui Business Co., Ltd., China.

\subsection{Apparatus}

The experimental apparatus in this work is shown in Figures 1 and 2. The apparatus in Figure 1 was the same as that in our previous work [9]. The crystallizer (CR) with inner volume of $336 \mathrm{~mL}$ and the supply vessel (SV) with the inner volume of $1350 \mathrm{~mL}$ were made of 316 stainless steels. They were immersed in a glycol-water bath. On the front and back of the $\mathrm{CR}$, there are two circular viewing windows made of Plexiglas. The maximum working pressure of the $\mathrm{CR}$ was $25 \mathrm{MPa}$. A magnetic stirrer $(500 \mathrm{r} / \mathrm{min})$ was employed to mix the contents in the CR. The temperatures of the gas phase and the liquid phase in the CR were measured using two Pt1000 thermocouples (JM6081) with uncertainties of $\pm 0.1 \mathrm{~K}$. The pressures in the SV and CR were measured with two Setra smart pressure transducers (model 552, Boxborough, MA, USA) with the uncertainty of $\pm 20 \mathrm{kPa}$. In addition, the composition of the gas phase in the CR was determined with a HP6890 gas

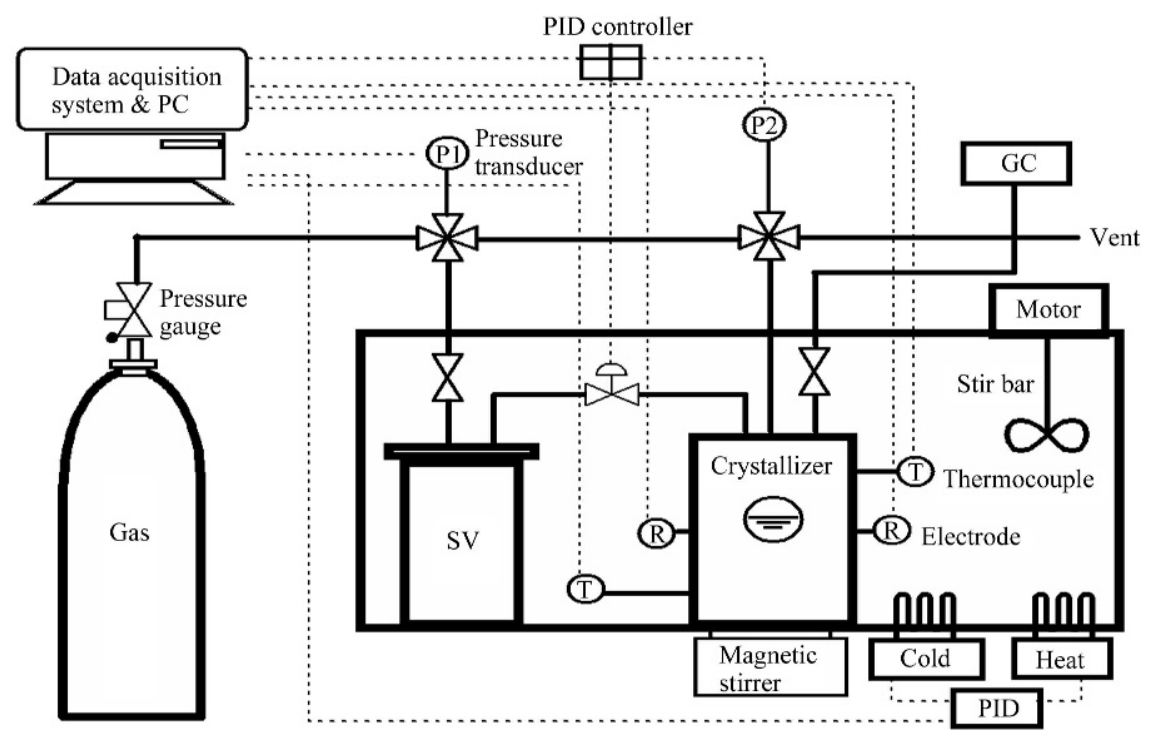

Figure 1. Experimental apparatus for hydrate process 
chromatograph (GC) connected on-line with $\mathrm{CR}$ and automated with a personal computer (PC). Figure 2 is one simulative $\mathrm{MEA} \mathrm{CO} \mathrm{CO}_{2}$ separation system. The round bottom flask (a) (as an absorption bottle) with effective volume of $500 \mathrm{~mL}$ was added into adequate quantities of glass-balls. Then $300 \mathrm{~mL}$ MEA solution of $30 \mathrm{wt} \%$ was added into the round bottom flask (a) and the solution surface was ensured to be $2-3 \mathrm{~mm}$ higher than the top of the glass-ball stack. The gas mixture was introduced into MEA solution by a right-angle glass tube, of which one terminal was inserted into the glass-ball stack. The other acute-angle glass tube was used for collecting $\mathrm{H}_{2}$, of which one terminal went through the rubber stopper. Another round bottom flask (b) was used as a stripper for regenerating MEA solution. The flask (b) was heated with a heater, and the released $\mathrm{CO}_{2}$ and the solution steam were collected via an acute-angle tube, of which one terminal was connected to a coiled condenser. The final gas was collected with a sealed gaseous envelope, then, it was detected with GC.
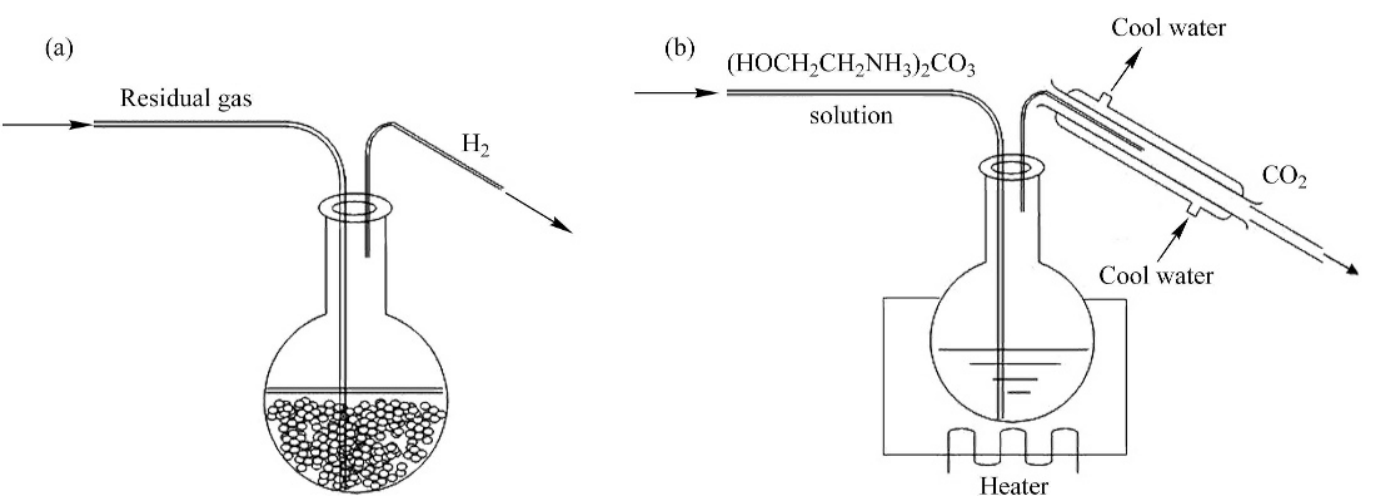

Figure 2. Experimental apparatus for $\mathrm{MEA} \mathrm{CO}_{2}$ separation. (a) Absorption bottle, (b) stripper for MEA regeneration

\subsection{Procedure}

TBAB solution with a desired concentration was introduced into the evacuated high-pressure cell. The content was pressurized up to the desired pressure by supplying $\mathrm{CO}_{2} / \mathrm{H}_{2}$ gas mixture. In this work, we firstly measured the equilibrium hydrate formation pressure for different $\mathrm{CO}_{2} / \mathrm{H}_{2}$ gas mixtures $\left(\mathrm{CO}_{2}\right.$ concentrations were $39.8 \mathrm{~mol} \%, 18.8 \mathrm{~mol} \%$ and 10.0 $\mathrm{mol} \%$, respectively) in the presence of TBAB. The method of three-phase equilibrium measurement adopted in the work was as same as the "T-cycle method" used by Ohgaki et al. [13]. Each "T-cycle" experiment was repeated for at least three times.

After equilibrium hydrate formation experiments, the procedure for hydrate stage was similar to that in our previous work $[9,14]$. The crystallizer (CR) was cleaned again using de-ionized water and allowed to dry. Then TBAB solution of $180 \mathrm{~mL}$ was introduced into the CR. Subsequently, the
$\mathrm{CR}$ is flushed with $\mathrm{CO}_{2} / \mathrm{H}_{2}$ gas mixture several times to remove gases, and then $\mathrm{CO}_{2} / \mathrm{H}_{2}$ gas mixture was charged into the CR until the desired pressure. Once the temperature was stabilized (typically within $1 \mathrm{~min}$ ), the stirrer with a rate of $500 \mathrm{r} / \mathrm{min}$ was started, and the experimental time was recorded once every two second. The time when the stirrer was started was defined as $t_{0}$. The data of temperature and pressure were recorded during the experiment. As the gas in the crystallizer was consumed because of the hydrate formation, additional gas mixture in the SV was supplied and the pressure in the crystallizer was kept constant with a proportional integral derivative (PID) controller. The measurement of the compositions and the amount of the gas consumed $\left(n_{\mathrm{H}}\right)$ as well as the calculation of $\mathrm{CO}_{2}$ separation efficiency were same as what mentioned in our previous work [10].

The hybrid process proposed in this work included a twostage hydrate-based process and a chemical absorption process. The mechanism of the chemical absorption process was based on the following reaction [15]:

$$
\begin{gathered}
\mathrm{CO}_{2}+2 \mathrm{HOCH}_{2} \mathrm{CH}_{2} \mathrm{NH}_{2}+\mathrm{H}_{2} \mathrm{O} \Longleftrightarrow\left(\mathrm{HOCH}_{2} \mathrm{CH}_{2} \mathrm{NH}_{3}\right)_{2} \mathrm{CO}_{3} \\
\left(\mathrm{HOCH}_{2} \mathrm{CH}_{2} \mathrm{NH}_{3}\right)_{2} \mathrm{CO}_{3}+\mathrm{CO}_{2}+\mathrm{H}_{2} \mathrm{O} \Longleftrightarrow 2\left(\mathrm{HOCH}_{2} \mathrm{CH}_{2} \mathrm{NH}_{3}\right) \mathrm{HCO}_{3}
\end{gathered}
$$

After two stages hydrate-based capture, the residue gas was introduced into a chemical absorption bottle, in which adequate amount of small glass-balls with the diameter of $3 \mathrm{~mm}$ and MEA solution of $30 \mathrm{wt} \%$ with desired volume had been added. $\mathrm{CO}_{2}$ was absorbed completely by MEA solution and formed the compounds of $\left(\mathrm{HOCH}_{2} \mathrm{CH}_{2} \mathrm{NH}_{3}\right)_{2} \mathrm{CO}_{3}$ and $\left(\mathrm{HOCH}_{2} \mathrm{CH}_{2} \mathrm{NH}_{3}\right) \mathrm{HCO}_{3}$ while $\mathrm{H}_{2}$ was not absorbed. Thus, $\mathrm{CO}_{2}$ is separated from IGCC synthesis gas, and $\mathrm{H}_{2}$ with high purity can be obtained. The pressure in the chemical absorption bottle was kept at 1.05 atm in order to ensure that the final gas can be collected easily. Then, the solution was introduced into a regeneration device, in which $\left(\mathrm{HOCH}_{2} \mathrm{CH}_{2} \mathrm{NH}_{3}\right)_{2} \mathrm{CO}_{3}$ and $\left(\mathrm{HOCH}_{2} \mathrm{CH}_{2} \mathrm{NH}_{3}\right) \mathrm{HCO}_{3}$ were heated to release $\mathrm{CO}_{2}$ and regenerate $\mathrm{MEA}$.

Based on the experiments, we further simulated $\mathrm{CO}_{2}$ separation process in a $500 \mathrm{MW}$ IGCC power plant with two $\mathrm{CO}_{2}$ 
separation methods. One was the three stages hydrate-based capture process, and the other was the hydrate/chemical absorption hybrid process. The difference of the two processes was the chemical absorption stage in the hydrate/chemical absorption hybrid process which substituted the third hydrate stage in three stages hydrate-based capture process. The first two hydrate stages were the same for the two processes. Thus, we only need to compare the energy consumptions between the third hydrate stage of the hydrate process and the chemical absorption stage of the hybrid process. The energy consumption was calculated according to the formula listed in the book of Advanced Engineering Thermodynamics [16].

\section{Results and discussion}

\subsection{Equilibrium hydrate formation pressure}

We firstly measured the equilibrium hydrate formation pressure for $\mathrm{CO}_{2} / \mathrm{H}_{2}$ gas mixture with $\mathrm{CO}_{2}$ concentration of $18.0 \mathrm{~mol} \%$ in $0.29 \%$ TBAB solution. Compared with the results given by $\mathrm{Li}$ et al. [17], it is found that the results were in excellent agreement, as shown in Figure 3. This illustrates either the apparatus or the method adopted in this work is reliable.

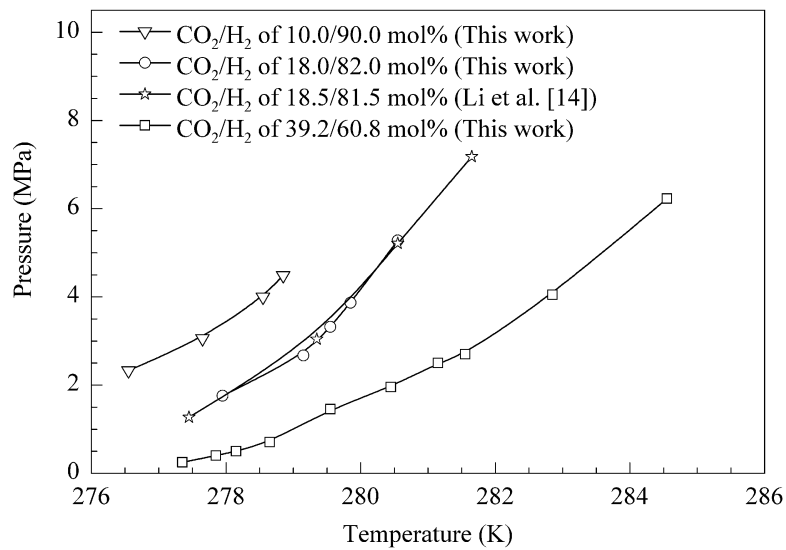

Figure 3. Equilibrium hydrate formation pressure for $\mathrm{CO}_{2} / \mathrm{H}_{2}$ gas mixtures in the presence of $0.29 \mathrm{~mol} \%$ TBAB solution

Figure 3 gives the measured equilibrium hydrate formation conditions for $\mathrm{CO}_{2} / \mathrm{H}_{2}$ gas mixtures with $\mathrm{CO}_{2}$ concentrations of $10.0,18.0$ and $39.2 \mathrm{~mol} \%$ in $0.29 \mathrm{~mol} \%$ TBAB solution. The pressure ranged from $0.25 \mathrm{MPa}$ to $6.23 \mathrm{MPa}$ and the temperature ranged from $276.55 \mathrm{~K}$ to $284.55 \mathrm{~K}$. The phase equilibrium data are summarized in Table 1. As shown in Figure 3 , the equilibrium hydrate formation pressure decreased considerably with the increase of $\mathrm{CO}_{2}$ in the gas mixture at the same temperature. For example, the equilibrium hydrate formation pressures were $3.45,1.80$ and $0.50 \mathrm{MPa}$ at $280.15 \mathrm{~K}$ for $\mathrm{CO}_{2} / \mathrm{H}_{2}$ mixtures with $\mathrm{CO}_{2}$ concentrations of $10.0,18.0$ and $39.2 \mathrm{~mol} \%$, respectively. In addition, the equilibrium temperatures at $4.0 \mathrm{MPa}$ were $278.15,279.75$ and $282.65 \mathrm{~K}$ for $\mathrm{CO}_{2} / \mathrm{H}_{2}$ mixtures with $\mathrm{CO}_{2}$ concentrations of $10.0,18.0$ and $39.2 \mathrm{~mol} \%$, respectively. The result illustrates that lower $\mathrm{CO}_{2}$ concentration in $\mathrm{CO}_{2} / \mathrm{H}_{2}$ mixture results in higher equilibrium pressure at the fixed temperature or higher equilibrium temperature at the fixed pressure, and further results in forming the gas hydrate more difficultly.

Table 1. Equilibrium hydrate formation pressure for $\mathrm{CO}_{2} / \mathrm{H}_{2}$ gas mixtures with different concentrations in $0.29 \mathrm{~mol} \%$ TBAB solution

\begin{tabular}{ccc}
\hline $\mathrm{CO}_{2} / \mathrm{H}_{2}$ gas mixtures & $T / \mathrm{K}$ & $P / \mathrm{MPa}$ \\
\hline $10.0 / 90.0 \mathrm{~mol} \%$ & 276.55 & 2.33 \\
& 277.15 & 2.72 \\
& 277.65 & 3.06 \\
& 278.65 & 4.00 \\
& 278.85 & 4.49 \\
$18.0 / 82.0 \mathrm{~mol} \%$ & 277.45 & 1.25 \\
& 277.95 & 1.76 \\
& 279.15 & 2.67 \\
& 279.85 & 3.87 \\
$39.2 / 60.8 \mathrm{~mol} \%$ & 280.55 & 5.28 \\
& 277.35 & 0.25 \\
& 277.85 & 0.40 \\
& 278.15 & 0.51 \\
& 278.65 & 0.71 \\
& 279.55 & 1.45 \\
& 280.45 & 1.96 \\
& 281.15 & 2.50 \\
& 282.85 & 4.05 \\
& 284.55 & 6.23 \\
\hline
\end{tabular}

\subsection{Hydrate-based $\mathrm{CO}_{2}$ separation}

Figure 4 gives the gas uptake changes with time for three $\mathrm{CO}_{2} / \mathrm{H}_{2}$ gas mixtures with $\mathrm{CO}_{2}$ concentrations of $10.0,18.0$ and $39.2 \mathrm{~mol} \%$ at $4.0 \mathrm{MPa}$ and $276.15 \mathrm{~K}$. A typical example is shown in Figure 4. There was an inflexion in the curve for $10.0 \mathrm{~mol} \% \mathrm{CO}_{2} / \mathrm{H}_{2}$ gas mixture at the 625 th second. The gas uptake increased slowly from 0 to $625 \mathrm{~s}$ while dramatically increased after the 625th second. At the 1830th second, the amount of gas uptake was $0.067 \mathrm{~mol}$, and then the amount of gas uptake had little change from the 1830th second to the end of the experiment. Similar phenomenon was also shown for $18.0 / 88.0 \mathrm{~mol} \% \mathrm{CO}_{2} / \mathrm{H}_{2}$ gas mixture. The gas uptake had a slight increase from 0 to $162 \mathrm{~s}$, then, it increased abruptly after the 162th second. At the 1945th second, the amount of gas uptake was $0.101 \mathrm{~mol}$. Subsequently, the amount of gas uptake had little change. For $39.2 / 60.8 \mathrm{~mol} \% \mathrm{CO}_{2} / \mathrm{H}_{2}$ gas mixture, the gas uptake increased slowly from 0 to $66 \mathrm{~s}$, and the amount of the uptake had a considerable increase from the 66th second to the 1578th second. At the 1578th second, the amount of gas uptake was $0.115 \mathrm{~mol}$, and subsequently it had little change. Similar to our previous work [10], the slow increase of the gas uptake are resulted from the dissolving of the gas mixture in TBAB solution while the abrupt increase of the gas uptake is attributed to the gas hydrate formation. Therefore, the time when the gas uptake turns to the increase abruptly is defined as the hydrate formation induction time [18]. Thus, as seen from Figure 4, the hydrate formation induction time for the three $\mathrm{CO}_{2} / \mathrm{H}_{2}$ gas mixtures at $4.0 \mathrm{MPa}$ and $276.15 \mathrm{~K}$ were 625,162 and $66 \mathrm{~s}$, respectively. The result illustrates that as $\mathrm{CO}_{2}$ concentration shifts to be lower, the hydrate formation 
induction time increases observably. It is attributed to the fact that the gas mixture with lower $\mathrm{CO}_{2}$ concentration has higher equilibrium hydrate formation pressure, and thus the corresponding driving force for the hydrate formation is lower, resulting in longer hydrate formation induction time [19]. However, for the hydrate-based $\mathrm{CO}_{2}$ separation, longer induction time is unfavorable for the application in industry. Thus, the hydrate formation induction time for $10.0 \mathrm{~mol} \% \mathrm{CO}_{2} / \mathrm{H}_{2}$ gas mixture of $625 \mathrm{~s}$, is too long to meet the requirement of industrial application for the hydrate-based $\mathrm{CO}_{2}$ separation.

In addition, as seen from Figure 4 , as $\mathrm{CO}_{2}$ concentration shifted to be lower in the gas mixture, the gas uptake decreased remarkably at $4.0 \mathrm{MPa}$ and $276.15 \mathrm{~K}$. For example, for the three $\mathrm{CO}_{2} / \mathrm{H}_{2}$ gas mixtures, the gas uptake obtained in this work were $0.067 \mathrm{~mol}, 0.101 \mathrm{~mol}, 0.115 \mathrm{~mol}$ when $\mathrm{CO}_{2}$ concentrations were $10 \mathrm{~mol} \%, 18.0 \mathrm{~mol} \%$ and $39.2 \mathrm{~mol} \%$, respectively. Although the gas uptakes obtained here were not

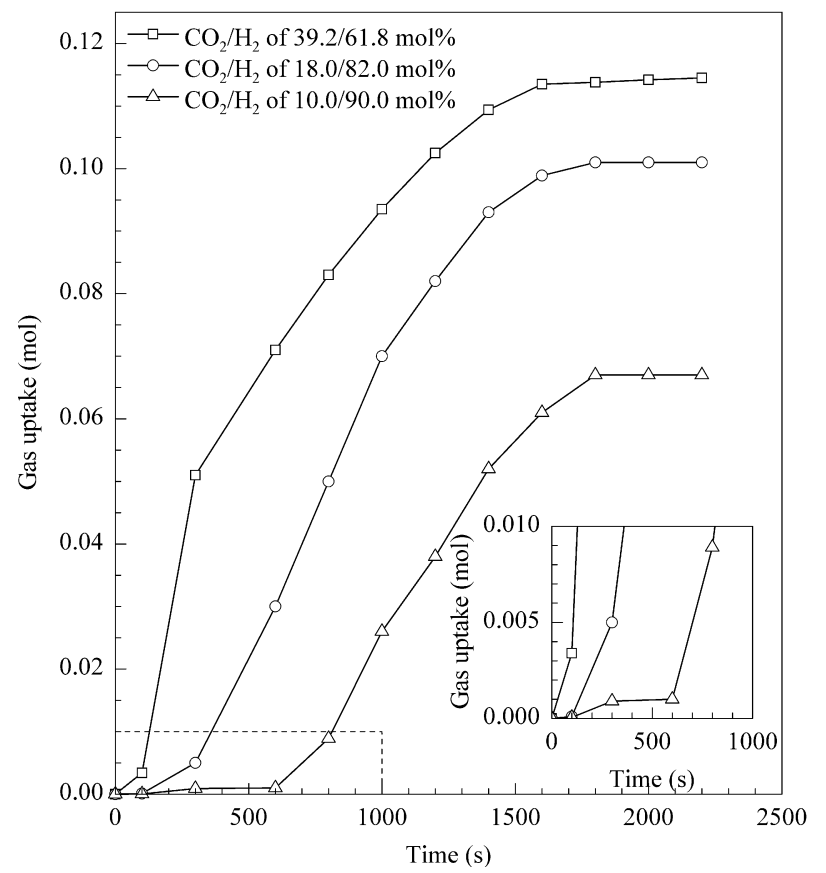

Figure 4. Gas uptake changes with time in the presence of $0.29 \mathrm{~mol} \%$ TBAB solution at $4.0 \mathrm{MPa}$ and $276.15 \mathrm{~K}$ high enough to meet the requirement of treating the large amount of IGCC synthesis gas in the industry, the shift tendency of the gas uptake with $\mathrm{CO}_{2}$ concentration change in the gas mixture indicates that higher $\mathrm{CO}_{2}$ concentration in the gas mixture is more helpful for the hydrate-based $\mathrm{CO}_{2}$ separation from IGCC synthesis gas.

Table 2 shows the hydrate-based $\mathrm{CO}_{2}$ separation efficiencies along with $\mathrm{CO}_{2}$ concentrations in the residual gas phase and hydrate slurry phase for the three different $\mathrm{CO}_{2} / \mathrm{H}_{2}$ gas mixtures at 4.0 MPa and $276.15 \mathrm{~K}$. As seen from Table 2, because $\mathrm{CO}_{2}$ concentration in the residual gas after the first and the second hydrate separation stages were $16.6 \mathrm{~mol} \%$ and $10.1 \mathrm{~mol} \%$, the values were close to $\mathrm{CO}_{2}$ concentration in the feed gas mixtures for the two stages $(18.0 \mathrm{~mol} \%$ and $10.0 \mathrm{~mol} \%$ ), respectively. Thus, a three stages hydrate-based $\mathrm{CO}_{2}$ separation process was proposed. The process flowchart is shown in Figure 5. As seen from Table 2, $\mathrm{CO}_{2}$ separation fraction and separation factor for $\mathrm{CO}_{2} / \mathrm{H}_{2}$ gas mixture of $39.2 / 60.8 \mathrm{~mol} / \mathrm{mol}$ were obviously larger than those for other two gas mixtures. As $\mathrm{CO}_{2}$ concentration shifted to lower, $\mathrm{CO}_{2}$ separation fraction and $\mathrm{CO}_{2}$ separation factor shifted to lower. For $\mathrm{CO}_{2} / \mathrm{H}_{2}$ gas mixtures with $\mathrm{CO}_{2}$ concentrations of $39.2 \mathrm{~mol} \%$ and $18.0 \mathrm{~mol} \%, \mathrm{CO}_{2}$ separation fractions were 0.66 and 0.62 , respectively, and $\mathrm{CO}_{2}$ separation factors were 72.3 and 19.4 , respectively. $\mathrm{CO}_{2}$ separation fraction and separation factor for $\mathrm{CO}_{2} / \mathrm{H}_{2}$ gas mixture with $\mathrm{CO}_{2}$ concentration of $10.0 \mathrm{~mol} \%$ were only 0.45 and 10.3 , respectively. The result illustrates that the hydrate-based $\mathrm{CO}_{2}$ separation from $\mathrm{CO}_{2} / \mathrm{H}_{2}$ gas mixtures with $\mathrm{CO}_{2}$ concentrations of $39.2 \mathrm{~mol} \%$ and $18.0 \mathrm{~mol} \%$ are feasible. Nevertheless, that from $\mathrm{CO}_{2} / \mathrm{H}_{2}$ gas mixtures with $\mathrm{CO}_{2}$ concentrations of $10.0 \mathrm{~mol} \%$ is unfeasible because of the quite low $\mathrm{CO}_{2}$ separation efficiency. Due to $\mathrm{CO}_{2}$ concentration in the feed gas mixture of the third hydrate stage was lower than $10.0 \mathrm{~mol} \%$, that separating $\mathrm{CO}_{2}$ and purifying $\mathrm{H}_{2}$ from IGCC synthesis gas via a whole three stages hydrate-based process is unfeasible. In other words, the continuous three stages hydrate-based $\mathrm{CO}_{2}$ separation process (as shown in the flowchart in Figure 5) is unfeasible. Consequently, it is necessary to develop a hybrid process for separating $\mathrm{CO}_{2}$ and purifying $\mathrm{H}_{2}$ from IGCC synthesis gas.

Table 2. Hydrate-based $\mathrm{CO}_{2}$ separation efficiencies along with $\mathrm{CO}_{2}$ concentrations in residual gas phases and hydrate slurry phases for three different $\mathrm{CO}_{2} / \mathrm{H}_{2}$ gas mixtures at 4.0 MPa and $276.15 \mathrm{~K}$ in this work

\begin{tabular}{|c|c|c|c|c|c|c|}
\hline Feed gas & $\begin{array}{l}\text { Gas uptake } \\
(\mathrm{mol})\end{array}$ & $\begin{array}{l}\text { Decomposed gas } \\
(\mathrm{mol})\end{array}$ & $\begin{array}{l}\mathrm{CO}_{2} \text { concentration in } \\
\text { residual gas phase }(\mathrm{mol} \%)\end{array}$ & $\begin{array}{l}\mathrm{CO}_{2} \text { concentration in } \\
\text { hydrate slurry phase }(\mathrm{mol} \%)\end{array}$ & $\begin{array}{c}\mathrm{CO}_{2} \text { separation } \\
\text { fraction }\end{array}$ & $\begin{array}{c}\mathrm{CO}_{2} \text { separation } \\
\text { factor }\end{array}$ \\
\hline $10.0 / 90.0 \mathrm{~mol}^{2} \mathrm{CO}_{2} / \mathrm{H}_{2}$ gas mixture & 0.067 & 0.0065 & 6.7 & 42.5 & 0.45 & 10.3 \\
\hline $18.0 / 82.0 \mathrm{~mol} \% \mathrm{CO}_{2} / \mathrm{H}_{2}$ gas mixture & 0.10 & 0.016 & 10.1 & 68.5 & 0.62 & 19.4 \\
\hline $39.2 / 60.8 \mathrm{~mol} \% \mathrm{CO}_{2} / \mathrm{H}_{2}$ gas mixture & 0.12 & 0.033 & 16.6 & 93.5 & 0.66 & 72.3 \\
\hline
\end{tabular}

\subsection{Chemical absorption of $\mathrm{CO}_{2}$}

On one hand, the amounts of MEA used for absorbing $\mathrm{CO}_{2}$ according to the Equation (1) depend on the amount of $\mathrm{CO}_{2}$ in the residual gas mixture. On other hand, the target for adopting less MEA in the process is strictly managed ow- ing to the environmental unfriendliness of MEA and the high energy consumption of the post-treatment for MEA. Therefore, one chemical absorption process is adopted to separate the residual gas released from the second hydrate stage. Figure 6 shows the flowchart of the hybrid $\mathrm{CO}_{2}$ separation process. Compared with the flowchart shown in Figure 5, the 


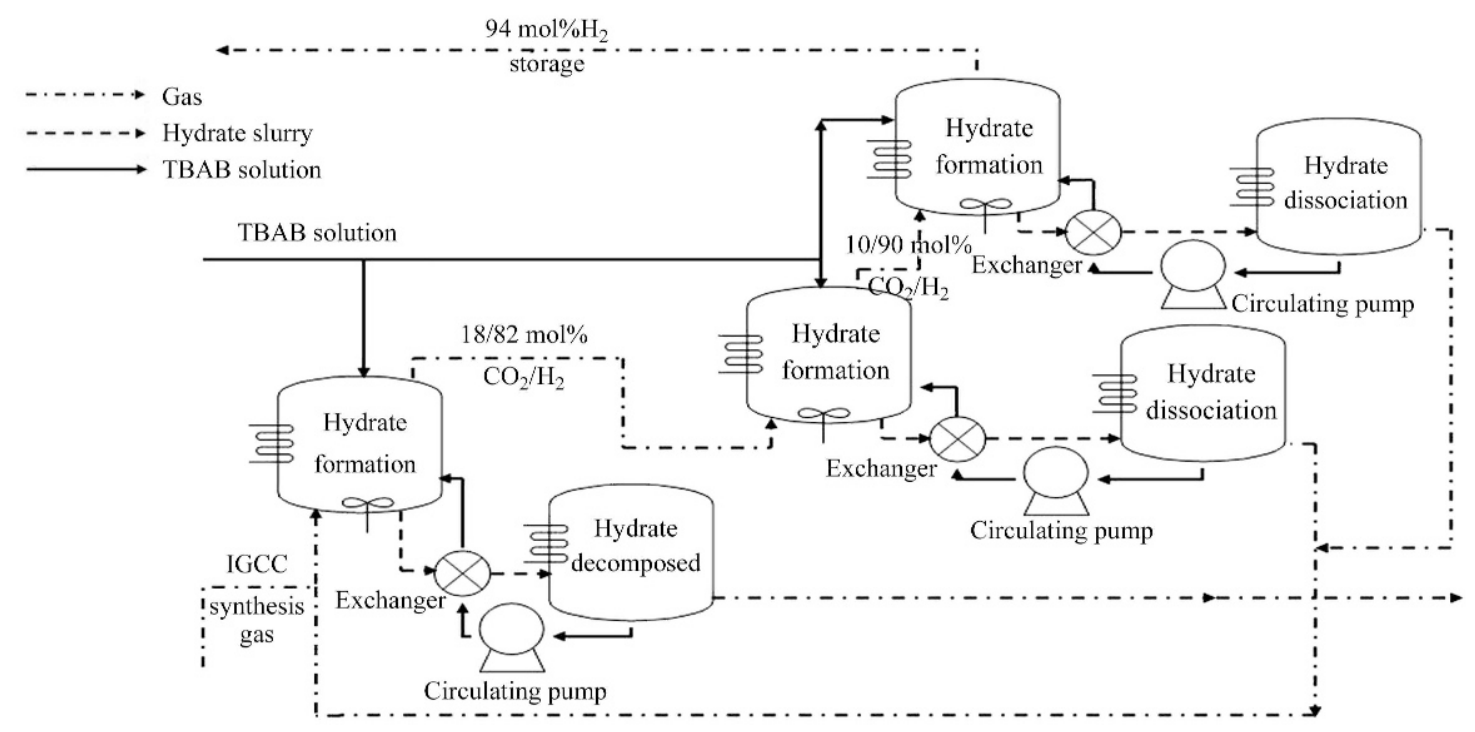

Figure 5. Flowchart for three hydrate-stage $\mathrm{CO}_{2}$ separation process

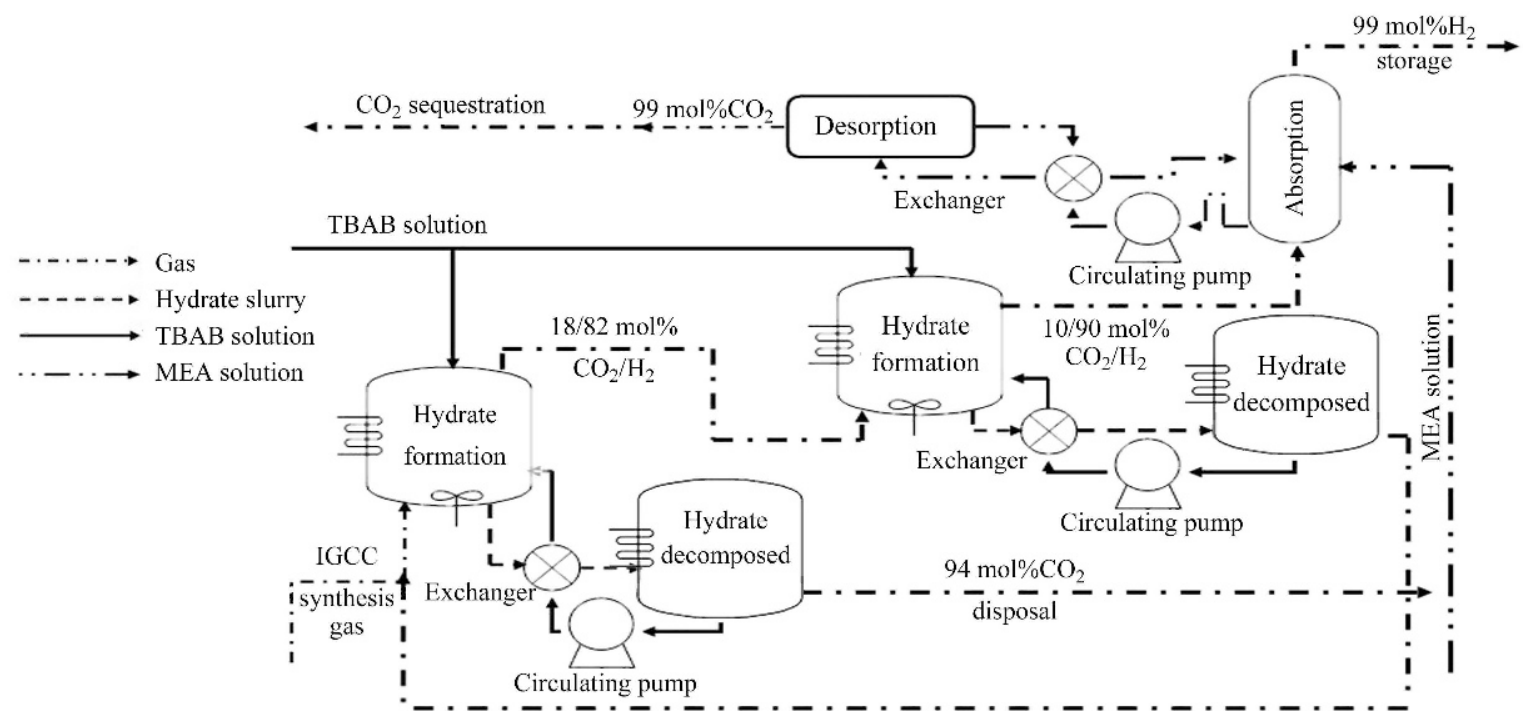

Figure 6. Flowchart for two hydrate-stage/chemical absorption hybrid $\mathrm{CO}_{2}$ separation process

third stage of the hydrate-based separation process was substituted by a chemical absorption and desorption process in Figure 6. Besides, the residual gas mixture produced in the second hydrate stage was directly introduced into $30.0 \mathrm{wt} \%$ MEA solution in the absorption tank. Because excess MEA was added in the absorption tank to absorb $\mathrm{CO}_{2}$ according to the Equation (1), all $\mathrm{CO}_{2}$ was considered to be adsorbed. In addition, in order to collect the gas mixture released from MEA solution easily at the outlet, the pressure difference of 0.5 atmosphere pressure was set between the inlet and outlet of the tank. The collected gas was almost pure $\mathrm{H}_{2}$ with purity of approximately $99.4 \mathrm{~mol} \%$. However, $\mathrm{H}_{2}$ concentration in the residual gas released from the third stage hydratebased $\mathrm{CO}_{2}$ separation process was approximately $95.2 \mathrm{~mol} \%$, as seen in Figure 7. Therefore, the concentration of $\mathrm{H}_{2}$ released from the chemical absorption separation process was

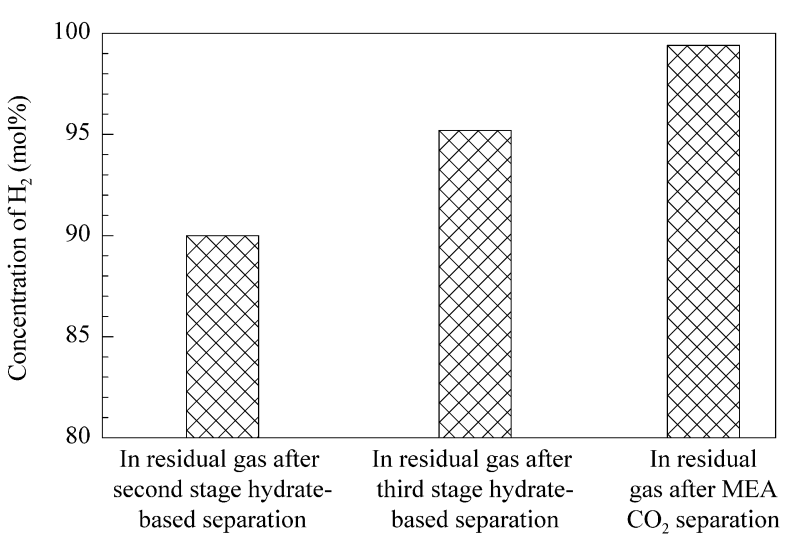

Figure 7. $\mathrm{H}_{2}$ concentrations in the residual gas after third stage hydrate-based $\mathrm{CO}_{2}$ separation and chemical absorption for feed gas coming from residual gas after second stage hydrate-based $\mathrm{CO}_{2}$ separation in this work 
4.2 mol\% which was higher than that released from the third stage hydrate separation process. Thus, it illustrates that hybrid $\mathrm{CO}_{2}$ separation process is feasible to obtain highly pure $\mathrm{H}_{2}$. However, the feasibility of hybrid $\mathrm{CO}_{2}$ separation process for the industrial application still needs reasonable energy consumption estimation and the estimation will be made in our next work.

\section{Conclusions}

The equilibrium hydrate formation pressures for $\mathrm{CO}_{2} / \mathrm{H}_{2}$ gas mixtures with $\mathrm{CO}_{2}$ concentrations of $10.0,18.0$ and $39.2 \mathrm{~mol} \%$ in the presence of $0.29 \mathrm{~mol} \%$ TBAB solution are firstly measured. The results illustrate that the equilibrium hydrate formation pressure increases remarkably with the decrease of the concentration of $\mathrm{CO}_{2}$ at the fixed temperature. Based on the above investigation, a hydrate-based $\mathrm{CO}_{2}$ separation from IGCC synthesis gas is studied for its environmentfriendly and economic features. In order to realize $\mathrm{CO}_{2}$ separation from IGCC synthesis gas efficiently, at least three hydrate stages are required. However, with the decrease of $\mathrm{CO}_{2}$ in $\mathrm{CO}_{2} / \mathrm{H}_{2}$ gas mixture, $\mathrm{CO}_{2}$ separation from the gas mixture becomes more difficult because of the increase of the corresponding equilibrium hydrate formation pressure. Especially for the third hydrate separation process, the equilibrium hydrate formation pressure shifts to high and the separation efficiency turns to quite low. Therefore, a hybrid $\mathrm{CO}_{2}$ separation process with two stages hydrate separation process in conjunction with one chemical absorption process (absorption with MEA) is proposed and analyzed. The experimental results show $\mathrm{H}_{2}$ concentration in the final residual gas released from the three stages hydrate $\mathrm{CO}_{2}$ separation process is approximately $95.0 \mathrm{~mol} \%$ while that released from the hybrid $\mathrm{CO}_{2}$ separation process is approximately $99.4 \mathrm{~mol} \%$. In this work, the energy consumption estimation is not studied, and it will be analyzed in our next work.

\section{Acknowledgements}

This work was supported by the National Natural Science Foundation of China (51076155)) and Science \& Technology Program of Guangdong Province (2009B050600006), which are gratefully acknowledged.

\section{References}

[1] Happel J, Hnatow M A, Meyer H. Ann N Y Acad Sci, 1994, 715: 412

[2] Freund P, Ormerod W G. Energy Conv Manag, 1997, 38: S199

[3] Klara S M, Srivastava R D. Environ Prog, 2002, 21: 247

[4] Linga P, Kumar R, Englezos P. J Hazard Mater, 2007, 149: 625

[5] Barchas R, Davis R. Energy Conv Manag, 1992, 33: 333

[6] Duc N H, Chauvy F, Herri J M. Energy Conv Manag, 2007, 48: 1313

[7] Zhu L, Fan Y. Appl Energy, 2011, 88: 4320

[8] Sloan E D ed. Clathrate Hydrates of Natural Gases, 3rd Ed. Golden: CRC Press, 2008

[9] Li X S, Xu C G, Chen Z Y, Wu HJ. Energy, 2010, 35: 3902

[10] Li X S, Xu C G, Chen Z Y, Wu H J. Energy, 2011, 36: 1394

[11] Li X S, Xia Z M, Chen Z Y, Wu H J. Energy Fuels, 2011, 25: 1302

[12] Linga P, Kumar R N, Englezos P. Chem Eng Sci, 2007, 62: 4268

[13] Ohgaki K, Makihara Y, Takano K. J Chem Eng Jpn, 1993, 26: 558

[14] Li X S, Xu C G, Chen Z Y, Wu H J, Cai J. J Nat Gas Chem, 2011, 20: 647

[15] Xu C G, Li X S, Chen Z Y, Cai J. CIESC J (Huagong Xuebao), 2011, 62: 1701

[16] Chen Z S. Advanced Thermodynamics Engineering. Beijing: Advanced Education Publisher, 2008

[17] Li X S, Xia Z M, Chen Z Y, Yan K F, Li G, Wu H J. J Chem Eng Data, 2010, 55: 2180

[18] Li X S, Xu C G, Chen Z Y, Cai J. Int J Hydrog Energy, 2012, 37: 720

[19] Herslund P J, Thomsen K, Solms N V. Thermodynamic and Process Modelling of Gas Hydrate Systems in $\mathrm{CO}_{2}$ Capture Processes, Edinburgh, Scotland, United Kingdom, 2011 